Etnográfica

Revista do Centro em Rede de Investigação em

Antropologia

vol. 19 (1) | 2015

Vol. $19(1)$

\title{
Representaciones de migrantes senegaleses en la sociedad porteña de Buenos Aires: apuntes sobre exotismo y exotización
}

Representations of Senegalese migrants in Buenos Aires: notes on exoticism and exoticization

Orlando Gabriel Morales y Gisele Kleidermacher

\section{(2) OpenEdition}

Journals

Edición electrónica

URL: https://journals.openedition.org/etnografica/3884

DOI: 10.4000/etnografica.3884

ISSN: 2182-2891

Editor

Centro em Rede de Investigação em Antropologia

Edición impresa

Fecha de publicación: 1 febrero 2015

Paginación: 29-50

ISSN: 0873-6561

Referencia electrónica

Orlando Gabriel Morales y Gisele Kleidermacher, «Representaciones de migrantes senegaleses en la sociedad porteña de Buenos Aires: apuntes sobre exotismo y exotización», Etnográfica [En línea], vol. 19 (1) | 2015, Publicado el 06 marzo 2015, consultado el 09 febrero 2022. URL: http:// journals.openedition.org/etnografica/3884 ; DOI: https://doi.org/10.4000/etnografica.3884

\section{(c) (†) \&}

Etnográfica is licensed under a Creative Commons Attribution-NonCommercial 4.0 International License. 


\section{Representaciones de migrantes senegaleses en la sociedad porteña de Buenos Aires: apuntes sobre exotismo y exotización}

\section{Orlando Gabriel Morales \\ y Gisele Kleidermacher}

Presentamos algunos registros de campo y reflexiones a modo de avance de dos investigaciones que tienen por objeto de estudio a la migración senegalesa reciente en Argentina y sus relaciones sociales en el contexto local, concretamente en las ciudades de Buenos Aires y La Plata. Específicamente, a partir de datos etnográficos, reflexionamos acerca del exotismo y la exotización como formas de percepción, relación y representación respecto de estas alteridades migrantes "negras". Nuestro análisis avanza en interpretar fenómenos que vinculamos con esos modos de construcción de la alteridad: una hipervisibilidad de las personas "negras" y el desconocimiento social respecto de África, los africanos y los afrodescendientes en el contexto local. Planteamos la hipótesis que el exotismo y la exotización de los recientes migrantes senegaleses se presentan en una relación de correspondencia/complementariedad con el proceso de invisibilización que pesó históricamente sobre los "negros" africanos y afrodescendientes en Argentina. Elaboramos una reflexión sobre las representaciones actuales al tiempo que contextualizamos las mismas en el marco de los procesos de alterización históricos de la sociedad nacional en relación con la población "negra" de origen africano.

PALABRAS-CLAVE: alteridad, migración africana, afrodescendientes, negrura, blanquedad, exotismo.

Representations of Senegalese migrants in Buenos Aires: notes on exoticism and exoticization - The paper presents some field registers and considerations resulting from two studies of the recent Senegalese migration in Argentina and the social relationships in the local context, particularly in the cities of Buenos Aires and La Plata. Specifically, based on ethnographic data, exoticism and exoticization are considered as ways of perception, relation to and representation of these "black" migrants' otherness. Two phenomena are interpreted as being associated with these ways of producing otherness, namely a hyper-visibility of "black" people and the social ignorance about Africa, African people and afro-descendents in the local context. Exoticism and the exoticization of recent Senegalese migrants are shown in connection or in a complementary relationship with the invisibilization process that historically affects the black African people and afro-descendents in Argentina. While focussing on current representations, they are contextualized in the historical national social processes of "othering" regarding the "black" population of African background. 
KEYWORDS: alterity, African migration, afro-descendants, blackness, whiteness, exoticism.

MORALES, Orlando Gabriel (omorales@mendoza-conicet.gob.ar) - Consejo Nacional de Investigaciones Científicas y Técnicas (Conicet), Agencia Nacional de Promoción Científica y Tecnológica (ANPCyT), Argentina.

KLEIDERMACHER, Gisele (kleidermacher@gmail.com) - Consejo Nacional de Investigaciones Científicas y Técnicas (Conicet), Universidad de Buenos Aires, Argentina.

\section{INTRODUCCIÓN}

Los datos y reflexiones que se presentan en este artículo corresponden a dos tesis doctorales que tienen algún grado de relación por involucrar aproximaciones etnográficas a un referente empírico común, por la localización del trabajo de campo realizado en cada caso y por el hecho de plantear preguntas de investigación en torno de problemas similares.

Referimos al proyecto "Representaciones de alteridades 'negras', africanas y afrodescendientes, en la sociedad nacional en Argentina”, desarrollado en el Doctorado en Comunicación de la Universidad Nacional de La Plata, en el que se analizaron procesos de alterización y representaciones de los "negros" en la sociedad argentina actual. Esa investigación involucró una aproximación etnográfica a migrantes africanos de la región subsahariana - la mayoría provenientes de Senegal - arribados recientemente a la Argentina y a interacciones entre estos y personas "no-negras" en las ciudades de La Plata y Ciudad Autónoma de Buenos Aires (CABA). ${ }^{1}$

Por su parte, el proyecto "Discriminación y racismo en Argentina: el caso de los migrantes del África Subsahariana”, en desarrollo en el Programa de Doctorado en Ciencias Sociales de la Universidad de Buenos Aires, plantea un estudio de las formas de discriminación y racismo en relación con los migrantes africanos subsaharianos, en el período 2000-2010. La investigación indaga las representaciones que elabora la población de diversos barrios de la CABA respecto de la migración en cuestión; las representaciones de los migrantes sobre los nativos y su acogida; los tipos de vínculos establecidos entre ambos colectivos; y el imaginario construido sobre la figura del "negro" y del inmigrante en la Argentina.

l La CABA es la Capital Federal de la República Argentina, mientras que La Plata es la ciudad capital de la Provincia de Buenos Aires y dista cincuenta kilómetros de la CABA, por lo que la circulación de personas y el intercambio comercial entre estos dos centros urbanos es regular y de relevancia. 
En este marco, con base en resultados y avances de las investigaciones aludidas, aquí reflexionamos sobre formas de representación en relación con los migrantes africanos - senegaleses - "negros" en la sociedad porteña actual.

Retomamos registros del trabajo etnográfico realizado en ambas investigaciones por medio de entrevistas a población nativa ("no-negra") y migrante ("negra") y de observaciones de interacciones cotidianas entre personas de ambos grupos.

Destacamos aquí el hecho de que los sujetos/grupos estudiados sean socialmente "negros" o "no-negros" (lo que equivale aquí a "blancos", aunque esta categoría es de uso casi nulo en las interacciones observadas) porque partimos de la premisa de que las relaciones entre migrantes africanos senegaleses y sujetos de la sociedad porteña están racializadas. ${ }^{2}$

Por racialización entendemos, siguiendo a Briones (1998), un proceso social de marcación de alteridad que apela a la idea de "raza", negando por este medio la posibilidad de que la diferencia/marca se disuelva a través de la miscegenación o la homogeneización cultural en una comunidad política.

Sin embargo, la dimensión racial no agota los aspectos involucrados en el proceso relacional/representacional estudiado, en el que observamos que intervienen también construcciones de sentido sustentadas en adscripciones/diferenciaciones culturales, de clase social, género y religión. ${ }^{3}$

Aunque aquí puntualizamos en modos de representación que apelan sobre todo a aspectos culturales y raciales y que son coherentes con el imaginario histórico respecto de las alteridades negras en la sociedad argentina, construido en función de un discurso dominante de la nación como - racialmente - blanca $\mathrm{y}$ - culturalmente - eurodescendiente.

En este sentido, a modo de hipótesis planteamos que las representaciones actuales de los migrantes senegaleses negros en la sociedad porteña se presentan en una relación de correspondencia/complementariedad con el proceso de invisibilización que pesó históricamente sobre la población negra africana y afrodescendiente en Argentina.

Por esto mismo, a continuación desarrollamos un breve panorama de los estudios de las alteridades africanas y afrodescendientes en Argentina, atendiendo a los aportes teóricos sobre los modos de alterización de estos grupos. Seguido a esto, especificamos los conceptos de exotismo y exotización, productivos en nuestro propio análisis.

2 Hasta aquí utilizamos la palabra "negro/a/s" entre comillas para indicar que tal categoría es una construcción social, lo mismo que la categoría "blanco/a/s". Dicho esto, en adelante prescindiremos del uso de comillas.

3 Si bien en este trabajo mencionaremos algunos aspectos de las representaciones de los migrantes africanos negros en la sociedad porteña vinculados con la intervención de las pertenencias/construcciones de clase social y género-sexo, en esta oportunidad nos centramos en "lo cultural" y "lo racial" como dimensiones relevantes de las formas contemporáneas de alterización de los negros en el contexto local. 
Más adelante, señalamos algunas características del grupo de migrantes africanos senegaleses e introducimos especificaciones sobre la configuración de lo que definimos como sociedad porteña. Luego presentamos una selección de registros etnográficos que aportan a una ulterior discusión; y, para finalizar, elaboramos una conclusión.

\section{PANORAMA DE LOS ESTUDIOS DE AFRICANOS Y AFRODESCENDIENTES}

En Argentina, como en el resto de los países de la región y del continente americano, la presencia de población africana se remonta al periodo de la trata de esclavos de África, durante la época colonial.

Sin embargo, la historiografía de las últimas tres décadas denuncia una subestimación histórica, cuantitativa y cualitativa, del componente africano en la sociedad argentina y la sociedad porteña de Buenos Aires, situación fundada en el ideal de nación de los sectores sociales y políticos dominantes en el momento de la gestación del Estado-nación moderno.

En tal sentido, la élite política y gobernante llamada "Generación del Ochenta" promovió e implementó a fines del siglo XIX un ingreso masivo de inmigrantes europeos que, según la perspectiva de este sector, contribuiría al "blanqueamiento" de la nación argentina. ${ }^{4}$ Así, buscaban modificar la estructura social transformando su composición étnica.

En definitiva, la nación argentina fue concebida y construida, en los discursos y en las prácticas, como predominante y preferentemente blanca y eurodescendiente; y las alteridades negras, entre otras, fueron negadas e invisibilizadas en la sociedad, identidad y memoria nacional (Andrews 1989 [1980]; Frigerio 2006, 2008; Geler 2008; Guzmán 2008).

En cuanto a los discursos que posibilitaron tal negación e invisibilización, algunos autores han demostrado la contribución de la literatura clásica nacional, en especial del siglo XIX y principios del siglo XX, a la represión/negación del componente poblacional negro con origen en los africanos esclavizados (Solomianski 2003). ${ }^{5}$

También hay quienes mostraron operaciones simbólicas de blanqueamiento por parte de los propios descendientes de africanos esclavizados a través de sus periódicos, en particular a fines del siglo XIX (Geler 2008; Cirio 2009).

4 Si bien la República Argentina se independizó de la corona española en el año 1810, el proceso político de apuntalamiento de un Estado-nación independiente y moderno implicó varias décadas de disputas y redefiniciones políticas internas. En ese marco, la llamada Generación del Ochenta - una élite intelectual, política y gobernante - actuó, durante un período que comprende los años 1880 a 1916, en la ejecución y consolidación de un proyecto de Estado-nación que en la actualidad se considera fundacional.

5 Cabe advertir que los estudios que citamos en relación con los afrodescendientes de Argentina han tomado centralmente por objeto de estudio a esta población en la sociedad porteña de Buenos Aires. 
Más todavía, se dice que al proceso de invisibilización puede haber aportado la escasez de la producción académica nacional, al menos hasta la década de 1980, en relación con temas atinentes a la población de origen africano en la sociedad nacional (Frigerio 2008).

En lo que refiere a los africanos migrados después de la coyuntura fundacional de la nación argentina moderna, Maffia (2010) y Correa (2000) señalan también un proceso de invisibilización de migrantes caboverdeanos arribados durante el siglo XX, aunque observan una "emergencia" y reivindicación de su identidad étnica a fines del mismo siglo.

Actualmente, la cuestión de la organización política de los afrodescendientes es objeto de estudio de múltiples investigaciones y hay avances concretos que dan cuenta de la mayor visibilidad de los afrodescendientes en Argentina (López 2005; Frigerio y Lamborghini 2010, 2011 ).

Este fenómeno de "reaparición" (Frigerio 2008) se habría originado, en parte, por un movimiento social de militantes negros, afroargentinos y migrantes afrodescendientes, que articuló el activismo político con un activismo cultural, que ya operaba desde la década de 1980 (Domínguez 2004; Frigerio y Lamborghini 2011).

Por otra parte, desde mediados de la década de 1990 se observa un nuevo contingente de migrantes africanos de la región subsahariana, en su mayoría de Senegal, que, además de generar mayor visibilidad social de las personas negras, se fue institucionalizando y comenzó a generar vínculos con los afrodescendientes en y de Argentina. ${ }^{6}$

A partir de esto se vienen desarrollando investigaciones con avances en la caracterización de tal población (Agnelli y Kleidermacher 2009; Maffia 2010, 2011 ), de las trayectorias migratorias (Chevalier-Beaumel y Morales 2012), de la conformación de redes sociales (Zubrzycki 2009) y de la inserción social local de los migrantes (Morales 2009, 2011).

Pese a todo, las representaciones sociales en la sociedad argentina en relación con los migrantes africanos y con los afrodescendientes, en y de Argentina, constituyen un objeto de estudio que todavía no ha sido suficientemente abordado.

Mencionamos ambos grupos porque consideramos que una reflexión sobre las representaciones que los tienen por objeto no debe perder de vista la concepción social de los africanos y afrodescendientes como personas "negras" y "extranjeras" en una sociedad autoconcebida como "blanca" y "sin negros" (Frigerio 2006).

6 Según los resultados del Censo Nacional del año 2010 en Argentina hay radicadas unas 2738 personas migrantes procedentes de países africanos, estimación que incluye a los originarios de la región subsahariana. Según el mismo censo, un total de 149.493 personas reconocieron ser afrodescendientes o tener antepasados de origen afrodescendiente o africano. Entre estos últimos, unas 137.502 personas declararon ser nativas de Argentina y el resto de otros países. 
Asimismo, hay que tener en cuenta los propios discursos de las asociaciones formadas por afroargentinos, migrantes africanos y afrodescendientes, que en general reivindican un origen africano común y problemáticas comunes en el contexto de la sociedad porteña y en Argentina - en especial aluden a la invisibilización y el racismo (Morales 2014).

Por nuestra parte, detectamos modalidades de construcción de los migrantes africanos - concretamente de los senegaleses - que hasta ahora habían sido escasamente aludidas - es el caso del exotismo y la exotización - en relación con la población negra de origen africano en la sociedad porteña de Buenos Aires y, en general, en la sociedad argentina.

\section{EXOTISMO Y EXOTIZACIÓN}

Según Segalen (2002 [1978]) la sensación de exotismo es la noción de diferencia, la percepción de la diversidad, el conocimiento de que algo o alguien es distinto. Así, concibe una complementariedad entre sensación de exotismo e individualismo, sin considerar la relación entre individuo y sociedad en la elaboración simbólica de lo propio y lo ajeno.

La incidencia de la individualidad, en la perspectiva de Segalen (2002 [1978]), implica que se pueden dar experiencias distintas según características de personalidad. De modo que no todas las personas tendrían la capacidad de gozar de lo diverso. Por esta vía, el autor distingue la experiencia del exota de la visión caleidoscópica del turista, en tanto que Todorov (2005 [1989]: 367-382) ha definido al exota como aquel que se entrega a la experiencia exótica, el sujeto que puede identificar al objeto y bloquear su asimilación y extrañarse, para preservar la alteridad y sentir el sabor de lo diverso.

En esta línea de pensamiento, el exotismo es un placer intenso por la alteridad. No implica por sí mismo un perjuicio para un sujeto o grupo específico concebido como exótico en el marco de relaciones sociales donde se definen pertenencia y ajenidad.

Incluso, Segalen (2002 [1978]) plantea salvaguardar el exotismo como percepción, vivencia y goce de la diversidad, contra el asimilacionismo, la relación superflua y la pretensión de comprensibilidad absoluta de lo diverso.

Así, de acuerdo con estas conceptualizaciones, el exotismo es una forma de percepción y representación de la diversidad cultural que pondera la diferencia sin llegar a concebirla como algo negativo o que debe ser incorporado en la homogeneidad supuesta de la cultura y del grupo social propio.

En base a lo expuesto, distinguimos exotismo de exotización. De acuerdo con Courtis (2000) y Morales (2005, 2011), entendemos que si bien el exotismo es una percepción común frente a la alteridad cultural, el discurso exotizante puede diferenciarse de aquel a partir de su capacidad de polarizar en forma deliberada las diferencias culturales. 
La exotización constituye una forma de representación de los Otros que no posibilita un modo de relación que no sea superficial, dado que se limita a identificar y reducir al Otro a algunos rasgos socialmente definidos como característicos y concebidos como esenciales - casi siempre del orden de "lo cultural" y eventualmente de "lo racial".

Tal representación se concreta por efecto de focalizar y sobredimensionar la diferencia del/de los "Otro/s" siempre en relación con un "Nosotros". De modo tal que la diferencia es destacada, naturalizada y esencializada y puede concebirse y/o constituirse como una barrera crucial para la comunicación y la integración social (Archenti y Morales 2010).

Exotización implica imputación de diferencia con una valoración negativa o positiva según el vínculo que se establezca con lo diverso y lejano. En efecto, uno de sus componentes es la lejanía (geográfica, temporal o moral) que establece el sujeto de representación respecto del objeto exotizado, eventualmente asociada a una idea de superioridad propia.

La atracción exotista hacia los sujetos/grupos culturales diversos y lejanos comparte con la estigmatización y el racismo el hecho de estar frecuentemente basada en un estereotipo que caricaturiza, homogeniza y confirma una distancia con aquello que se percibe como exótico (Frigerio 2004).

Desde la perspectiva que sostenemos, el pasaje del exotismo a la exotización es equivalente al pasaje del goce de la diferencia (sobre todo cultural, pero no únicamente) del/de los Otro/s hacia su reducción e incomprensión con base en la misma.

En este artículo referimos, en particular, a la visibilidad extrema o hipervisibilidad como una manifestación del exotismo de los migrantes africanos - negros - en la sociedad porteña. Siguiendo a Archenti y Morales (2010), la visibilidad extrema debe entenderse considerando el otro extremo: la invisibilidad social.

La visibilidad extrema y la invisibilidad producen efectos positivos o negativos de acuerdo a los sujetos involucrados y el contexto socio-histórico específico en que se manifiestan. La visibilidad social extrema, en términos de imposibilidad de pasar desapercibido/a, puede resultar tan opresiva como la invisibilidad (Archenti y Morales 2010).

En nuestra perspectiva, la actual visibilidad - a veces extrema - de los migrantes africanos negros - tal es nuestra tesis para el caso de los senegaleses - y la invisibilidad de los afrodescendientes en la sociedad porteña de Buenos Aires son construcciones sociales históricas configuradas por la convergencia y apelación de múltiples aspectos y discursos.

\section{SOCIEDAD PORTEÑA Y LAS NUEVAS PRESENCIAS AFRICANAS}

La mayor parte de los estudios sobre la migración africana actual en Argentina se centran en Buenos Aires, en parte por la densidad poblacional de esta región, 
que generalmente se considera en una extensión que excede a la Ciudad de Buenos Aires y abarca el "Gran Buenos Aires" o la Región Metropolitana de Buenos Aires. ${ }^{7}$

Además, históricamente se ha concebido a la Ciudad de Buenos Aires como el centro gubernamental, político, comercial y cultural de la República y al puerto de esta ciudad como la vía de contacto con el exterior. Todo esto aporta a la centralidad que tiene esta ciudad y región en el imaginario hegemónico de la nación argentina. De modo que es bastante común que en los trabajos académicos se considere, algunas veces de modo explícito y otras de manera implícita, que aquello que se dice sobre el imaginario de la sociedad porteña, en particular, sea aplicable o extrapolable también en términos generales a la sociedad argentina.

Sin embargo, la sociedad porteña es bastante heterogénea y desigual como para que sean pertinentes algunas generalizaciones sin aclaraciones previas. Un intento cerrado o poco reflexivo de evidenciar las formas de alterización actual de los negros de origen africano en la sociedad porteña puede llevar a un énfasis homogeneizador en torno de la blancura y la europeidad como rasgos identitarios autoproclamados de la sociedad local.

Entonces, hay que decir que en este trabajo referimos centralmente a una muy pequeña porción de la población de Buenos Aires - y la Región Metropolitana - que tiene contacto ocasional con los migrantes senegaleses que tomamos como nuestros interlocutores en el marco de las etnografías realizadas, especialmente en sus lugares de trabajo.

Lo anterior implica que, dada la actividad laboral predominante de los migrantes senegaleses en el contexto local (la venta ambulante de algunos productos de uso personal de bajo costo), se trata de varones - mayoritariamente y mujeres de diversas edades, de sectores sociales que consumen los productos que los migrantes comercializan.

En términos de una estratificación social, las personas en contacto con los migrantes son predominantemente parte de sectores que pueden ser considerados como "medios" y "bajos", condición social que potencialmente incide en el establecimiento y marcación de cercanías y/o distancias simbólicas entre unos y otros en el marco de la sociedad mayor.

Incluso, en tanto que en el discurso sobre la estratificación y las diferencias sociales en la sociedad porteña los factores de raza o color han sido desplazados hacia los de clase social (Frigerio 2006), es posible que los sectores

7 Según datos del último Censo Nacional de Población, Hogares y Vivienda, correspondiente al año 2010, "el Gran Buenos Aires reúne 12.801.364 habitantes, conformando uno de los aglomerados urbanos más extensos del mundo. De esta población, 2.891.082 habitantes residen dentro de los límites de la ciudad de Buenos Aires. Por su parte, la Región Metropolitana de Buenos Aires reúne 14.819.137 habitantes, concentrando el 37\% de la población del país" (Maceira 2012). Tal región incluye la Ciudad de La Plata y otros cuarenta municipios de la provincia de Buenos Aires. 
mencionados disputen desde una posición desfavorable su propia legitimidad dentro de la configuración del "Nosotros". ${ }^{8}$

Tal situación puede merecer una discusión sobre el nivel de participación/aceptación de estas personas y los sectores sociales de referencia en relación con el discurso hegemónico de la sociedad porteña como blanca y eurodescendiente.

Pero aquí partimos de la premisa de que, en tanto se trata de una construcción hegemónica, el imaginario de la blanquedad y europeidad de la sociedad porteña es, en términos relativos, compartido.

Por su parte, el nuevo contingente de migrantes africanos negros en la Ciudad de Buenos Aires y la Región Metropolitana de Buenos Aires está compuesto predominantemente por varones de varias nacionalidades del África subsahariana.

Esta nueva migración de africanos se inició en la década de 1990 y, aunque se considera que por tratarse de una migración con alto grado de irregularidad en los modos de ingreso al país los datos oficiales no dan cuenta de la cantidad real de personas ingresadas y radicadas, las estadísticas estatales existentes permiten apreciar su crecimiento poblacional.

El Censo Nacional de Población, Hogares y Vivienda del año 2001 cuantificó la población proveniente de África radicada en el país en 1.883 personas; mientras que el censo realizado en el año 2010 registró 2.738 personas, lo que representa un crecimiento de casi el 50 por ciento en diez años. ${ }^{9}$

En el caso de la migración senegalesa, predominan los varones jóvenes (de entre 20 y 40 años), con educación escolarizada de nivel medio y en Buenos Aires dedicados al trabajo informal (sobre todo la venta ambulante o callejera de bijouterie y accesorios corporales/personales de bajo costo), aunque algunos migrantes tienen formación universitaria o actualmente realizan estudios universitarios; y también hay quienes están empleados en trabajos formales

8 En el ámbito de las clasificaciones de alteridades sociales al interior de la nación argentina, la categoría "negro/s" tiene más de una acepción y uso social. En el discurso social se puede registrar el uso de la palabra "negros", con comillas, para referir a aquellos grupos sociales considerados de clase social baja o empobrecida, los mismos que en las interacciones cotidianas contemporáneas suelen clasificarse como "cabezas" o "negros villeros" - los que en otra coyuntura histórico-política se denominaron "cabecitas negras” (Ratier 1971). Para mayor profundidad sobre el uso social de estas categorías, véanse los trabajos de Ratier (1971), Frigerio (2006) y Morales (2012).

9 Más allá de estos datos, es probable que una parte considerable de los migrantes africanos recientes no estén incluidos en las cuantificaciones por autoexclusión de los operativos censales (debido a su condición migratoria irregular). Además, hay que decir que las cuantificaciones mencionadas incluyen a todas las nacionalidades africanas en el país, lo que involucra a los migrantes de África del Norte. Por otra parte, si se considera que en el último censo nacional, del año 2010, se registraron 149.493 personas afrodescendientes, la población de migrantes africanos es considerablemente menor que la de afrodescendientes de y en Argentina, hecho que suma relevancia al fenómeno de la visibilidad de los migrantes africanos frente a la histórica invisibilidad de los afrodescendientes. 
(Maffia y Agnelli 2008; Agnelli y Kleidermacher 2009; Kleidermacher 2012a, $2012 b)$.

En su gran mayoría son practicantes de la religión islámica e incluso en la Ciudad de Buenos Aires hay presencia de instituciones religiosas y de redes de migrantes vinculadas a la cofradía Mouride (Zubrzycki 2009). ${ }^{10}$

Otra cuestión significativa es que los migrantes senegaleses son hablantes del idioma francés y de al menos un dialecto - en su mayoría wolof, que usan sobre todo hacia el interior del grupo de pertenencia -, hecho que tiene implicancias en las relaciones interculturales y en las representaciones de ellos en la sociedad argentina (Morales 2014).

\section{REGISTROS DE LOS TRABAJOS ETNOGRÁFICOS}

En entrevistas con algunos migrantes estos manifestaban que su presencia en los lugares de residencia o en espacios de circulación de personas, donde habitualmente trabajan, es percibida con extrañeza. Incluso, hay quienes mencionaron haber sido objeto de observación y señalamiento discriminatorio por el hecho de "ser negros" y "extranjeros".

Varios de nuestros interlocutores migrantes manifiestan - con distintas palabras - haber tenido alguna vez la "sensación de ser una pieza de un zoológico” [M., notas de campo de O.G.M., marzo de 2008], por ser objeto de contemplación, señalamiento o de burlas de personas no negras de la sociedad porteña.

En concordancia con lo anterior, nuestras observaciones en contextos de comunicación interpersonal han permitido constatar que algunas personas no negras tocan, miran y expresan curiosidad y fascinación por la piel de los migrantes negros. También escuchamos algunos comentarios discriminatorios con referencias a su olor corporal.

Un registro realizado durante una jornada de trabajo de campo, que presentamos aquí como un relato, permite representarse una situación del tipo mencionado en las interacciones interpersonales entre migrantes y personas de la sociedad porteña.

"Aminata llega temprano al mismo lugar de siempre y arma su puesto.

Enseguida se acerca una señora mayor. Saluda a Aminata con una sonrisa, mientras le toma la cara con las dos manos.

Sí, parece simple: ya con la cara entre sus manos, la mira y le sonríe. Dura apenas unos segundos. Cualquiera diría: iqué actitud cariñosa!

10 La cofradía Mouride es una orden islámica que tiene como referente espiritual a Ahmadou Bamba y está presente especialmente en Senegal y Gambia, aunque ha adquirido carácter transnacional a partir de la emigración de estos países. 
Un momento después se acerca otra mujer. Le toca la piel, se la observa. Esta vez es más claro: una actitud de revisación médica.

Y una enésima, le dice:

- iAy que lindo color de piel, me encanta...!

Después de todo esto, casi como un corolario, un hombre que circula por la vereda se aproxima a Aminata y le regala una rosa...

Parece algo casual, como si el sujeto se hubiera encontrado primero con la rosa y luego con la negra y para dar continuidad a la sucesión de accidentes determinó que la rosa y la negra se juntaran en su recorrido.

Pero, después de todo, vale preguntarse: ¿Habrá alguna relación entre el obsequio de la rosa y el color de la piel?"

(Morales 2009: 28)

Una situación similar a la anterior observamos en ocasión en que un grupo de adolescentes salían de un local de comidas rápidas y comenzaron a usar sus teléfonos móviles con cámaras fotográficas incorporadas para tomarse fotografías junto a un joven senegalés que comercializaba algunos productos en forma ambulante en la puerta del local de comidas.

Repetían: "Sácame una foto con 'Guido", haciendo alusión al migrante senegalés - aunque ese nombre era una invención y le fue impuesto como seudónimo para la ocasión -, pero sin hacer una solicitud concreta en forma directa. Finalmente, el joven senegalés decidió acercarse a ellos y les dijo que no tenía problema en que le tomaran una fotografía.

Ante tal episodio consultamos a nuestro interlocutor migrante qué sentimientos le suscitaba esa situación. Él respondió que es algo que ocurre todo el tiempo y que no es molesto que le tomen una fotografía sólo o con otra persona, pero que si tiene que hacerlo con cada una de las personas interesadas "podría estar horas" sin trabajar.

Nuestro interlocutor también mencionó que es algo que ocurre sobre todo cuando trabaja durante la temporada de verano en la playa, lugar donde mucha gente solicita a él y a sus connacionales sacarse fotos porque "al ser negros, llama la atención" [notas de campo de G. K., julio de 2011 ].

A la estrecha asociación entre negrura y el hecho de "llamar la atención" se suma, en algunos comentarios registrados, un elemento más: el supuesto brillo de la bijouterie, que aparentemente en combinación con los otros elementos hace a un conjunto especialmente "llamativo" para los transeúntes y potenciales clientes.

Existe además una idea generalizada entre las personas de la sociedad porteña, a juzgar por la frecuencia con que se manifiesta en las interacciones observadas, de que la bijouterie que comercializan los migrantes es traída de África, hecho que en apariencia suma exoticidad y despierta interés por la procedencia de los migrantes y de los productos. 
Sin embargo, dejando de lado estas asociaciones, la pregunta por la procedencia es muy común y se plantea como un modo de iniciar una conversación. Muchas de nuestras primeras interacciones con los migrantes empezaron por esta pregunta, que por ser común no deja de ser, para muchos de ellos, una muestra de un extrañamiento que los agobia. Ese estado de ánimo se desprende del relato con el que representamos un encuentro con un nigeriano:

"Una mañana mientras hacía un registro fotográfico en el puesto de venta de $\mathrm{CH}$, un migrante nigeriano, se hizo presente otro migrante nigeriano que había decidido visitar a su 'hermano'.

Nos saludamos. Ya nos habíamos visto días antes en un encuentro casual cuando ambos concurrieron a la conmemoración por el Día de Las Américas en la Municipalidad de La Ciudad de La Plata, invitados por la referente de una asociación de inmigrantes uruguayos que en distintas oportunidades había convocado a $\mathrm{CH}$ para que 'represente' al colectivo uruguayo en festividades (ya que él hace percusión y era invitado en función de ese aporte y de su condición de negro).

Después de unos minutos, me sentí movilizado a hacerle a este nuevo interlocutor las preguntas de rigor sobre el tiempo de estadía aquí y el lugar de su última residencia, entre otras cuestiones habitualmente aludidas en encuentros de este tipo.

Pero el intercambio no duró mucho, pues enseguida se echó a reír mientras me decía: 'Todo el mundo hace esas preguntas aquí. La gente pregunta mucho, siempre: iHola! - simulando un tono de voz femenina -, ¿de dónde sos?... ¿de África? iAy que lindo!... Uno se cansa de responder siempre lo mismo. ¿Es que no hay negros aquí? iSí, hay! Aquí en Argentina también hay negros." (Morales 2009: 150)

Estas referencias nos informan en algún grado sobre la imposibilidad de los migrantes africanos de pasar desapercibidos en la sociedad porteña. Negrura y extranjeridad se articularían como diacríticos en las identificaciones que hacen las personas de la sociedad mayor sobre aquella parcialidad.

Más todavía, en una entrevista realizada a un referente institucional del colectivo senegalés en la Ciudad de Buenos Aires, éste nos transmitió sus temores por las consecuencias de esta visibilidad en relación con la inserción laboral de los migrantes:

"Las autoridades van a empezar a perseguirnos muchísimo más [se refiere a una persecución por parte de la Policía y de agentes de la Dirección Nacional de Migraciones], ahora somos más o menos dos mil quinientos [senegaleses] y todos piensan que somos un millón. Somos muchos en los ojos de los argentinos y de las autoridades. 
Imagínate cuando lleguemos a diez mil senegaleses, que no es nada para una migración [...] ¿Que vamos a parecer en los ojos de la gente? Muchísimos, ¿vamos a poder estar en la calle en ese momento? No." [Notas de campo de G. K., abril de 2014]

Para nosotros esta pregunta sobre la imagen que tienen las personas de la sociedad porteña se hizo presente de forma inmediata en el marco de los primeros encuentros en distintos espacios (plazas, calles, veredas, paseos, ferias y centros comerciales de las ciudades de Buenos Aires y La Plata) con migrantes - varones y mujeres - senegaleses, negros.

Durante esos encuentros no pasaron inadvertidas las miradas escudriñadoras de las personas (no negras) de la sociedad porteña. Ser una mujer blanca interactuando con hombres negros o ser un hombre blanco que dialoga o camina con mujeres negras parece causar extrañeza y despertar algunos prejuicios en quienes observan.

En parte, adjudicamos la actitud de extrañeza y el acto de escudriñar a una representación que asocia a las personas negras con una dote sexual o una sexualidad exacerbada. De hecho, en alusión a nuestras propias relaciones en el marco de la investigación recibimos insinuaciones y valoraciones por parte de terceros fundadas en supuestos sexuales.

Por su parte, los propios migrantes con quienes hemos tenido contacto dan cuenta de situaciones de seducción, insinuación o de propuestas explícitas en relación con lo sexual, también de acoso sexual con base en la idea de dotes sexuales y de promiscuidad de los negros.

Otras representaciones asignan a los migrantes ciertos rasgos bien valorados socialmente, pero esas concesiones suelen estar relacionadas con prejuicios. La valoración de algunos como personas "muy trabajadoras" suele vincularse con el prejuicio de que los africanos son, antes que agentes sociales activos, "víctimas" de la pobreza, las guerras, las epidemias.

La misma concepción lleva a algunas personas de la sociedad mayor a tener actitudes de compasión con los migrantes. Tal es el caso que pretendemos representar con el siguiente relato elaborado a partir de registros de campo:

"Una mujer se acerca a otra. La primera vende anillos en la calle, la otra se ha convertido en una clienta habitual que compra adornos corporales como obsequios para parientas lejanas, amigas y conocidas.

La vendedora destina lo recaudado al pago del hotel, la comida del día y la reposición de lo vendido. Si 'sobra' un dinero - cuando no se tiene un mal día algo ‘sobra' - se envía a la familia en Senegal.

La compradora utiliza los productos para cumplir con pautas de cortesía. Es, a la vez, un símbolo de distinción, que expresa una posición social. El ejercicio de un poder adquisitivo que le permite gastar en obsequios 
para terceros y ejercer la solidaridad, o tal vez la compasión, según dice antes de marcharse: iYo te compro para ayudarte, querida!" (Morales 2009: 28)

En general, entre nuestros interlocutores no negros, la presencia de población africana negra en la sociedad argentina se asocia con la pobreza extrema en África y, en algunos casos y en forma concomitante, con la falta de aptitudes personales que justificarían la precariedad de los trabajos de los migrantes.

"En su país también hacían eso. Vender lo que tenían para obtener otra cosa, es por historia." [Vendedor de diarios, notas de campo de G. K., octubre-noviembre de 2011]

"El que conozco se viste bastante bien. Al principio era medio Tarzán, pero después se fue re-acomodando a la sociedad. Al principio no usaba ni bóxer, porque se le notaba mucho algo y lo dejaba colgando." [Encargada de un local de indumentaria, notas de campo de G. K., octubre-noviembre de $2011]$

"Muchos son de Puerto Rico, son negritos. Viven en el campo, comen lo que plantan, por eso acá sólo compran hueso." [Vendedora ambulante, notas de campo de G.K., octubre de 2011]

Tales sentimientos, percepciones y representaciones parecen sustanciarse más en estereotipos y prejuicios que en un conocimiento elaborado a partir de relaciones sociales concretas y sostenidas en el tiempo.

Por esto mismo, presuponemos que los medios de comunicación tienen un rol importante en la formación y circulación de tales imágenes, aunque no es nuestro objetivo profundizar aquí en esta cuestión.

\section{DISCUSIÓN}

Cuando aquí referimos a la visibilidad - o hipervisibilidad - de los migrantes senegaleses enfatizamos en las representaciones que emergen desde la sociedad porteña, aunque a estas puede aportar la coyuntura de "hipervisibilidad de las diferencias" en discursos de actores globales y estatales (Grimson 2006) y las políticas de reconocimiento de los afrodescendientes por parte del Estado argentino (López 2005).

Incluso puede incidir en esta visibilidad la propia intervención en la arena pública de los migrantes en forma institucional, a partir de su articulación con actores supraestatales, estatales y organizaciones de afrodescendientes para reclamar al Estado argentino por el cumplimiento de sus derechos y para manifestarse contra el racismo (Morales 2014). 
Pero en lo sustancial esta visibilidad es una construcción social etnocentrada que se configura por apelación a múltiples aspectos identificados como ajenos, vinculados sobre todo a lo cultural (religión, vestimenta, lengua) y racial (fenotipo). ${ }^{11}$

Asimismo, es una construcción elaborada sobre la idea de "extinción" de los negros de la sociedad porteña y, consecuentemente, de "extranjeridad" y "extrañeza" de los africanos negros que ahora son "visibles" en el contexto local.

Los registros mencionados en el apartado anterior muestran que los migrantes conocen, al menos en términos generales, la relación de negación de la sociedad porteña con los negros descendientes de africanos esclavizados que son parte de la población, así como la inclinación al extrañamiento y la curiosidad frente a los negros.

Los dichos de quien se fastidia frente a las mismas preguntas - "iEs que no hay negros aquí? iSí, hay! Aquí en Argentina también hay negros” - dejan ver, además del conocimiento que se tiene de la situación mencionada, que el énfasis explicativo se coloca en la negrura.

El propio migrante citado menciona la negrura como elemento de tensión, que explica, desde su perspectiva, la curiosidad; la negrura cuya existencia social previa necesita afirmar para desnaturalizar la negación.

También las referencias al hecho de sentirse percibidos como "una pieza de un zoológico" y los registros que dejan ver modos singulares de acercamiento personal - por caso, la mujer que acaricia la cara de una migrante senegalesa remiten al extrañamiento, la contemplación y fascinación como manifestaciones del exotismo.

En orden de avanzar en esta línea interpretativa y para pensar un fenómeno social detectado en el marco de nuestros trabajos de campo, al que definimos como "desconocimiento social", retomamos la tesis de Mills (2007) acerca de lo que define como "ignorancia blanca".

Por nuestra parte, con la noción de desconocimiento social buscamos enfatizar el carácter colectivo, compartido y co-construido del desconocimiento de los afrodescendientes, los africanos y de África, en general, en la sociedad porteña de Buenos Aires.

Mills (2007) plantea que la condición necesaria para la naturalización de la idea de la blanquedad (es decir, del cuerpo blanco como "cuerpo normal") en una sociedad es la institución de una "ignorancia blanca" como ficción

11 Por esto mismo y porque no es nuestro objetivo en este artículo analizar la articulación de las perspectivas obtenidas de las etnografías con otros discursos (del Estado, de los medios de comunicación u otros) es que nuestros aportes se circunscriben aquí a identificar sobre qué aspectos se sustenta lo que interpretamos como un fenómeno de visibilidad - en algunas situaciones, extrema - de los migrantes senegaleses desde su propia perspectiva y la de la sociedad porteña de Buenos Aires. 
o mentira racista articulada en función de determinados intereses económico-simbólicos. ${ }^{12}$

La "ignorancia blanca", en términos de Mills (2007), implica operaciones de olvido y de desaprender acerca de conocimientos efectivos. Así, siguiendo a este autor, la ignorancia es una construcción social orientada al cumplimiento de determinados intereses de una sociedad auto-concebida como blanca.

Por su parte, Frigerio (2006) sostiene que la blanquedad de la sociedad porteña requiere de un trabajo de construcción social de la realidad que implica invisibilización de los negros afrodescendientes en un nivel micro y macro-social: en las interacciones cotidianas y en el discurso de la historia e identidad cultural de la nación.

A nivel micro-social, se asigna la categoría de negro a quien posee el cabello mota, la piel "negra, negra" y la nariz ancha (Frigerio 2006). Así, en un contexto de mestizaje de los afrodescendientes, se favorece la idea común de que "en Argentina no hay negros"; y, en el caso de los migrantes senegaleses, se confirma la extranjeridad de la negrura.

Asimismo, la blanquedad porteña resulta de un proceso socialmente construido y mantenido, en parte, según Frigerio (2006), por el desplazamiento, en el discurso sobre la estratificación y las diferencias sociales, de factores de raza o color hacia los de clase social.

En sintonía con estos planteos, sostenemos que en este caso el desconocimiento social apuntala la naturalización de la - supuesta - blanquedad de la sociedad porteña y refuerza la invisibilización de elementos sociales, culturales, "raciales" que la contradicen o la ponen en entredicho.

Por su parte, la histórica negación/invisibilización de los negros de origen africano en la sociedad porteña puede haber contribuido a la construcción de este desconocimiento social sobre los afrodescendientes y, por extensión, sobre África y los africanos en general.

En consecuencia, agregamos, por efectividad social del desconocimiento alcanzado y por efecto de permanencia del mismo, es posible y factible el exotismo y la reproducción de estereotipos y prejuicios sobre las personas negras de origen africano.

El supuesto de que la bijouterie que comercializan los migrantes es traída de África sólo puede tener sentido - o tener lugar en el sentido común - por el hecho que duplica su exoticidad o por ser una suposición que emerge de un

12 Aunque Mills (2007) plantea su tesis para el contexto de la sociedad nacional estadounidense, donde - según el autor - la categorización de raza funciona como el primer criterio de división social, consideramos que su planteo contribuye a pensar los mecanismos de construcción de la blanquedad aún en un contexto social donde las relaciones, al menos en apariencia, se "desracializaron" en función de otros criterios - en especial, la etnicidad - organizadores de las diferencias al interior de la nación. 
desconocimiento profundo de la realidad económica de los países de origen de estos y de sus condiciones de vida.

El mismo desconocimiento y el conocimiento erróneo o la generalización a partir de casos favorecen el prejuicio de que los africanos son, por sobre cualquier otra condición, víctimas de la miseria.

Una parte de los comentarios antes mencionados, de quienes tienen contacto con los migrantes en cuestión - el vendedor de diarios, una encargada de un local de indumentaria, una vendedora ambulante -, sostienen esta idea común.

En otro orden de ideas, obsérvese que quienes se expresan en este sentido no parecen pertenecer, a juzgar por su inserción laboral, a una clase social diametralmente distinta a la de los migrantes.

Esto muestra, por una parte, qué sector social tiene contacto cotidiano con estos migrantes; y, por otra, que las representaciones manifiestas, que se supone que emergen de los sectores dominantes de la nación y la sociedad porteña, tienen pregnancia en la parcialidad social en contacto directo con los migrantes.

Llama la atención, por otra parte, cierta contradicción en el hecho de suponer que África es un territorio signado por la pobreza y, a la vez, que estos migrantes pueden tener capacidad económica de exportar bijouterie hacia el continente americano.

En todo caso esto podría tener explicación si se considera, con Segalen (2002 [1978]), que el exotismo es una percepción del orden de lo sensorial, más que una representación reflexiva.

Por otra parte, la forma de la visibilidad actual de los migrantes senegaleses deja ver, desde nuestro punto de vista, la imposibilidad de pasar desapercibido en una sociedad donde la negación, la invisibilidad y el borramiento del negro de origen africano de la historia social dieron lugar a la creencia de que "en Argentina no hay negros".

Creemos que así como el exotismo se produce frente a lo distinto y desconocido, es posible también por un contexto previo de invisibilidad del objeto de exotismo. Lo mismo se puede decir para la visibilidad social extrema, aunque entendemos que uno y otro fenómeno no tienen las mismas consecuencias sociales para los sujetos involucrados.

En el contexto actual, los migrantes senegaleses se hacen visibles como Otros por marcaciones de alteridad que parecen centrarse en su diversidad de fenotipo y en su procedencia extranjera (que en vez de clasificarse por nacionalidad recibe el etiquetamiento continental: "africana").

Así lo deja ver la mujer que se manifiesta "encantada" por el color de piel de Aminata, la interpretación de un migrante respecto de que "ser negros llama la atención" de los bañistas, el agobio que expresa otro por ser consultado acerca de su procedencia; la preocupación de un referente por la visibilidad de los senegaleses ante las "autoridades". 
Con su presencia, estos nuevos migrantes contradicen la idea de ausencia de negrura e incluso se afirman en su alteridad sin negarse a sí mismos para fundirse en la pretendida blanquedad de la sociedad porteña de Buenos Aires.

El hecho de que el mencionado $\mathrm{CH}$, nigeriano, acepte ser convocado para "representar" en festividades públicas a la colectividad de Uruguay en Argentina - frente a la ausencia de uruguayos que quieran asumir ese rol - deja ver su propio posicionamiento en torno de las clasificaciones sociales propias y de la sociedad local.

Así también, el hecho en cuestión muestra que quienes convocan a $\mathrm{CH}$ lo hacen desde el imaginario que asocia negrura y extranjeridad, al punto que su participación es aceptable en tanto lo hace en representación de una nacionalidad extranjera y en la medida que la sociedad porteña sí asocia a Uruguay con la presencia e identidad cultural negra.

En este marco, que entendemos como el resultado de la concreción histórica de un proyecto hegemónico de Estado-nación, los nuevos migrantes africanos se hacen aprehensibles al conocimiento de las personas de la sociedad porteña a partir de una serie de estereotipos que dan sentido a lo desconocido.

Asimismo, en las representaciones de la sociedad porteña opera una exotización de los migrantes senegaleses que es palpable en modalidades de construcción de su ajenidad que implican una polarización respecto de esta población, estereotipada y considerada como otredad radical. De este modo, los migrantes senegaleses son ubicados en un extremo de las alteridades de la sociedad porteña y su presencia se destaca sobre todo por la visibilidad asignada socialmente a la negrura, a la vez que a ésta se asocian dotes no necesariamente bien valoradas.

Además, la focalización en estas alteridades no implica mayor grado de sociabilidad o de aceptación de las mismas. Por el contrario, la visibilidad de los negros, su imposibilidad de pasar desapercibidos, los ubica en el lugar de objeto de contemplación y de estigmas sociales.

En algún punto, exotización y estigmatización parecen entrelazarse. Posiblemente este entrecruzamiento pueda estar asociado a que en uno y otro modo de representación/relación se hace presente la idea de la propia superioridad del individuo que exotiza o estigmatiza.

Se sabe también que la homogeneización estereotípica de individuos bajo una categoría social obtura a la mirada la heterogeneidad y marca a estos con determinado/s atributo/s que se concibe/n como una esencia. En ese sentido, hemos registrado estereotipos, prejuicios y actitudes desfavorables para una inserción social equitativa de los migrantes.

En este punto, algunas cuestiones mencionadas al exponer registros de los trabajos etnográficos merecen ser retomadas. Entre ellas, la cosificación que supone la asociación entre la negrura corporal de los migrantes, el brillo de la bijouterie y el hecho de "llamar la atención" de las personas de la sociedad 
local. Esta cosificación se puede identificar también en la actitud de quien toca la piel de una migrante a modo de "revisación médica" y en la sensación del migrante que se siente "una pieza de zoológico". Algo similar cabe decir sobre el caso de los jóvenes que pretenden sacarse una foto con "Guido", pero aquí la cosificación llega al punto que son los jóvenes quienes inventan un personaje con un nombre propio - cercano a ellos - que deberá actuar el migrante.

Surgen, entonces, dos preguntas. Por una parte, ¿estas referencias nos hablan de la "atención" que despiertan los migrantes africanos recientes en la sociedad porteña o, en cambio, de la "atención" que pone la sociedad porteña sobre los migrantes africanos? Por otra parte, ¿se trata de una cuestión de sensación de extrañeza frente a la alteridad o de una representación que construye y sobredimensiona lo extraño en relación con lo familiar?

Creemos que las últimas referencias dicen más acerca de una relación superflua y de un intento de hacer asimilable lo extraño, a partir de estereotipos y categorías propias, que del goce y la preservación de la diversidad. Con una orientación semejante pueden interpretarse las manifestaciones acerca de la sexualidad.

Hemos dicho que en alusión a nuestra propia relación con migrantes africanos/as, negros/as, en el marco de la investigación registramos abundantes insinuaciones y valoraciones fundadas en supuestos sexuales. Más todavía, dijimos que los propios migrantes con quienes hemos tenido contacto dan cuenta de situaciones de seducción, insinuación o de propuestas explícitas en relación con lo sexual. En otro orden de hechos, en uno de los relatos expuestos, el migrante que reacciona demostrando agobio por la recurrente pregunta sobre la procedencia representa la voz que lo interpela (que se supone es de una persona de la sociedad porteña) en una voz femenina - o más precisamente, por su alocución, afeminada.

Todo esto invita a pensar las relaciones entre sexualidad y raza en las representaciones estudiadas, aunque no ahondaremos en ello. Pero cabe decir que la asignación de una "hiper-sexualidad" (Wamsley 2005) parece ser parte de un sobredimensionamiento de las diferencias - construidas y valoradas negativamente - respecto de la sociedad porteña.

Wamsley (2005) usa el término hiper-sexualidad al referirse a las representaciones de los esmeraldeños y los ecuatorianos en general sobre los esmeraldeños negros como personas calientes, y señala que el término caliente es algo ambiguo. Por un lado, puede tener un sentido de reconocimiento de una habilidad especial de los esmeraldeños negros: la destreza en el baile; mientras que, por otro lado, remite a la sangre caliente como un valor negativo y asociado a la hiper-sexualidad y otras cuestiones que en esa sociedad son mal vistas.

En sintonía, cuando aquí hablamos de percepciones y representaciones que oscilan entre el exotismo y la exotización, del pasaje del goce de la diversidad a la reducción de la diversidad con base en las diferencias, referimos 
a alterizaciones con algún grado de ambigüedad, en que la diversidad puede ser percibida de un modo y, casi a la vez, ser representada en forma divergente.

\section{CIERRE}

Hasta aquí hemos planteado sólo algunas líneas de análisis respecto de las representaciones de los migrantes senegaleses en la sociedad porteña, a sabiendas que no es posible agotar el tratamiento de la cuestión en esta instancia.

Nos ocupamos en particular del exotismo y la exotización como formas de alterización de los migrantes senegaleses y señalamos a la invisibilidad social de los afrodescendientes de y en Argentina y el desconocimiento social de estos y de los africanos y los asuntos vinculados a África como condiciones de posibilidad de estas alterizaciones.

En términos generales, referimos al extrañamiento, la contemplación y la fascinación como manifestaciones del exotismo de los migrantes senegaleses en la sociedad porteña. También, señalamos la incidencia de la construcción de negrura y extranjeridad en relación con su visibilidad.

Destacamos la visibilidad y visibilidad extrema en tanto fenómenos asociados a la construcción de los senegaleses, negros, como esencialmente diferentes y ajenos. Es decir, fenómenos sociales vinculados a su exotización, que implica imposibilidad de pasar desapercibidos, cosificación y sometimiento a comportamientos invasivos.

Queda pendiente, entre otras cuestiones posibles, indagar con mayor profundidad las relaciones entre la histórica invisibilización de los negros de origen africano en la sociedad nacional y lo que definimos aquí como exotismo y exotización de las nuevas presencias de origen africano en Argentina.

Para eso, incluso todavía es necesario avanzar más, desde una mirada histórica, en el análisis de los procesos y mecanismos que contribuyeron a la invisibilización de los descendientes de africanos esclavizados en la sociedad nacional y porteña.

\section{BIBLIOGRAFÍA}

AGNELLI, Silvina, y Gisele KLEIDERMACHER, 2009, “Migración estacional de senegaleses en Mar del Plata”. Ponencia presentada en la VIII Reunión de Antropología del Mercosur, Buenos Aires.

ANDREWS, George Reid, 1989 [1980]), Los Afroargentinos de Buenos Aires. Buenos Aires, Ediciones La Flor. 
ARCHENTI, Adriana, y Orlando G. MORALES, 2010, “Selección excluyente y valoración: migrantes extranjeros en la prensa escrita local”, en Alejandro Verano (ed.), Medios de Comunicación en la Argentina: Diagnóstico y Prospectiva. La Plata, Ediciones de Periodismo y Comunicación, 19-40.

BRIONES, Claudia, 1998, La Alteridad del "Cuarto Mundo": Una Deconstrucción Antropológica de la Diferencia. Buenos Aires, Ediciones del Sol.

CHEVALIER-BEAUMEL, Ellen, y Orlando G. MORALES, 2012, "Aproximación etnográfica a la nueva migración africana en Argentina: circulación y saberes en el caso de los senegaleses arribados en las últimas dos décadas", Astrolabio: Nueva Época, 8: 381-405.

CIRIO, Pablo Norberto, 2009, Tinta Negra en el Gris del Ayer. Buenos Aires, Editorial Teseo. CORREA, Natalia Otero, 2000, Afroargentinos y Caboverdeanos: Las Luchas Identitarias contra la Invisibilidad de la Negritud en la Argentina. Misiones, Universidad Nacional de Misiones, disertación de maestría.

COURTIS, Corina, 2000, Construcción de Alteridad: Discursos Cotidianos sobre la Inmigración Coreana en Buenos Aires. Buenos Aires, Eudeba.

DOMÍNGUEZ, Maria E., 2004, O "Afro" entre os Imigrantes em Buenos Aires: Reflexões sobre as Diferenças. Florianópolis, Universidade Federal de Santa Catarina, disertación de maestría en Antropología Social.

FRIGERIO, Alejandro, 2004, "Migrantes exóticos: los brasileros en Buenos Aires", Runa, 25 : 97-121.

FRIGERIO, Alejandro, 2006, “'Negros' y 'Blancos' en Buenos Aires: repensando nuestras categorías raciales”, en Leticia Maronese (comp.), Buenos Aires Negra: Identidad y Cultura. Buenos Aires, Comisión para la Preservación del Patrimonio Histórico Cultural de la Ciudad de Buenos Aires, 77-98.

FRIGERIO, Alejandro, 2008, “De la 'desaparición' de los negros a la 'reaparición’ de los afrodescendientes: comprendiendo la política de las identidades negras, las clasificaciones raciales y de su estudio en la Argentina", en Gladys Lechini (comp.), Los Estudios Afroamericanos y Africanos en América Latina: Herencia, Presencia y Visiones del Otro. Córdoba, Centro de Estudios Avanzados; Buenos Aires, Consejo Latinoamericano de Ciencias Sociales, 117-144.

FRIGERIO, Alejandro, y Eva LAMBORGHINI, 2010, "Criando um movimento negro em um país ‘branco': ativismo político e cultural afro na Argentina”, Afro-Asia, 39: 153-181.

FRIGERIO, Alejandro, y Eva LAMBORGHINI, 2011, “(De)mostrando cultura: estrategias políticas y culturales de visibilización y reivindicación en el movimiento afroargentino”, Boletín Americanista, 63: 101-120.

GELER, Lea, 2008, ¿“Otros” Argentinos? Afrodescendientes Porteños y la Construcción de la Nación Argentina entre 1873 y 1882 . Barcelona, Universitat de Barcelona, disertación doctoral.

GRIMSON, Alejandro, 2006; "Nuevas xenofobias, nuevas políticas étnicas en Argentina”, en Grimson Alejandro y Jelin Elizabeth (comp.), Migraciones Regionales hacia Argentina: Diferencia, Desigualdad y Derechos. Buenos Aires, Prometeo, 69-98.

GUZMÁN, Florencia, 2008, "Mulatización, indianización y banqueamiento en la sociedad colonial de Catamarca: análisis de un ejercicio”, en Nora Siegrist, y Maria Ghirardi (comp.), Mestizaje, Sangre y Matrimonio en Territorios de la Actual Argentina y Uruguay, Siglos XVII-XX. Córdoba, Centro de Estudios Avanzados, 143-161.

KLEIDERMACHER, Gisele, 2012a, "Migración sur-sur: senegaleses en la Ciudad de Buenos Aires", Voces en el Fénix, 21: 107-119. 
KLEIDERMACHER, Gisele, 2012b, "Migraciones subsaharianas a la Argentina: interacción, integración o exclusión”, Ánfora, 32 (19): 91-116.

LÓPEZ, Laura Cecilia, 2005, “iHay alguna persona en este hogar que sea Afrodescendiente?” Negociações e Disputas Políticas em Torno das Classificações Étnicas na Argentina. Porto Alegre, Universidade Federal de Rio Grande do Sul, disertación de maestría en Antropología Social.

MACEIRA, Verónica, 2012, "Notas para una caracterización del Área Metropolitana de Buenos Aires". Polvorines (Buenos Aires), Instituto del Conurbano, Universidad Nacional de General Sarmiento, disponible en: < http://www.ungs.edu.ar/ms_ico/wpcontent/uploads/2012/02/Informe-sobre-Región-Metropolitana-de-Buenos-Aires-ICO -UNGS.pdf > (09/05/2014, ultima consulta en enero 2015).

MAFFIA, Marta M., 2010, Desde Cabo Verde a la Argentina: Migración, Parentesco y Familia. Buenos Aires, Biblos.

MAFFIA, Marta M., 2011, "La migración subsahariana hacia Argentina: desde los caboverdianos hasta los nuevos migrantes del siglo XXI”, en Gabriela Catterberg y Rubén Mercado (coords.), Aportes para el Desarrollo Humano en Argentina/201 1: Afrodescendientes y Africanos en Argentina. Buenos Aires, Programa de las Naciones Unidas para el Desarrollo, 53-89.

MAFFIA, Marta M., y Silvina AGNELlI, 2008, "Primeras aproximaciones al estudio de la nueva inmigración africana en la Argentina", en Anuario 2008 del Instituto de Relaciones Internacionales. La Plata, Ediciones IRI-UNLP, 1-11.

MILLS, Charles W., 2007, "White ignorance", en Shannon Sullivan y Nancy Tuana (eds.), Race and Epistemologies of Ignorance. Albany, State University of New York Press, 13-38.

MORALES, Orlando G., 2005, "El discurso exotizante: el caso del barrio chino en la prensa nacional", Tram(p)as de la Comunicación y la Cultura, 42: 30-37.

MORALES, Orlando G., 2009, Africanos del Oro 14: La Migración Negra hacia Argentina en el Siglo XXI. La Plata, edición del autor.

MORALES, Orlando G., 201 1, "Representaciones gráficas acerca de la otredad: una lectura comunicacional de dibujos de autóctonos sobre inmigrantes", Intersecciones en Comunicación, 5: 89-112.

MORALES, Orlando G., 2012, "Categorías identitarias en el campo afro: nudos de sentido y representaciones disputadas", Question, 35: 17-32.

MORALES, Orlando G., 2014, Representaciones de Alteridades "Negras", Africanas y Afrodescendientes, en la Sociedad Nacional en Argentina: Primera Década del Siglo XXI. La Plata, Universidad Nacional de La Plata, disertación de doctorado en Comunicación.

RATIER, Hugo, 1971, El Cabecita Negra. Buenos Aires, Centro Editor de América Latina.

SEGALEN, Victor, 2002 [1978], Essay on Exoticism. Durham y Londres, Duke University Press.

SOLOMIANSKI, Alejandro, 2003, Identidades Secretas: La Negritud Argentina. Rosario, Beatriz Viterbo.

TODOROV, Tzevan, 2005 [1989], Nosotros y Los Otros. México, DF, Siglo XXI.

WAMSLEY, Emily, 2005, “'Bailando como negro’: ritmo, raza y nación en Esmeraldas, Ecuador", Tabula Rasa, 3: 179-195.

ZUBRZYCKI, Bernard, 2009, "La migración senegalesa y la diáspora mouride en Argentina". Ponencia presentada a la VIII Reunión de Antropología del Mercosur, Buenos Aires. 